\title{
Childhood mortality and its association with household wealth in rural and semi-urban Burkina Faso
}

\author{
Anja Schoeps ${ }^{a, *}$, Aurélia Souares ${ }^{a}$, Louis Niamba ${ }^{b, c}$, Eric Diboulob,d, Gisela Kynast-Wolfa ${ }^{a}$ Olaf Müller ${ }^{a}$, \\ Ali Siéb and Heiko Bechera
}

${ }^{a}$ Institute of Public Health, University of Heidelberg, 69120 Heidelberg, Germany; ${ }^{b}$ Centre de Recherche en Santé de Nouna, Nouna, Burkina Faso; 'Département de Démographie, Université de Montréal, H3T 1N8 Montréal, Canada; ${ }^{d}$ Swiss Tropical and Public Health Institute (Swiss TPH), 4051 Basel, Switzerland

*Corresponding author: Tel: +49 622156 7758; Fax: +49 622156 5948; E-mail: schoeps@uni-heidelberg.de

Received 22 November 2013; revised 14 May 2014; accepted 14 May 2014

\begin{abstract}
Background: This study aimed to investigate the relationship between household wealth and under-5 year mortality in rural and semi-urban Burkina Faso.

Methods: The study included 15543 children born between 2005 and 2010 in the Nouna Health and Demographic Surveillance System. Information on household wealth was collected in 2009. Two separate wealth indicators were calculated by principal components analysis for the rural and the semi-urban households, which were then divided into quintiles accordingly. Multivariable Cox proportional hazards regression was used to study the effect of the respective wealth measure on under-5 mortality.
\end{abstract}

Results: We observed 1201 childhood deaths, corresponding to 5 -year survival probability of $93.6 \%$ and $88 \%$ in the semi-urban and rural area, respectively. In the semi-urban area, household wealth was significantly related to under- 5 mortality after adjustment for confounding. There was a similar but non-significant effect of household wealth on infant mortality, too. There was no effect of household wealth on under-5 mortality in rural children.

Conclusions: Results from this study indicate that the more privileged children from the semi-urban area with access to piped water and electricity have an advantage in under-5 survival, while under- 5 mortality in the rural area is rather homogeneous and still relatively high.

Keywords: Africa south of the Sahara, Child mortality, Household wealth, Principal components analysis, Rural-urban difference, Social class

\section{Introduction}

Although infant and child mortality have decreased over the past years, numbers are still too high to reach Millennium Development Goal 4, which is the reduction of child mortality by two-thirds between 1990 and 2015.,.$^{1,2}$ This is particularly obvious for Sub-Saharan Africa, where recent data show that the under-5 mortality risk has decreased only from 178 to 109 from 1990 to 2011. ${ }^{1}$ Child mortality in Burkina Faso has decreased from 205 per 1000 in 1993 to 142 per 1000 in 2006, which corresponds to an average annual decrease of about $2.8 \%$, which is not sufficient to reach Millennium Development Goal 4 . $^{3}$

According to the Demographic and Health Survey in Burkina Faso from 2010, there is a pronounced difference in childhood mortality between urban and rural areas. ${ }^{4}$ This difference in mortality in children under 5 years old has also been observed in the Nouna
Health and Demographic Surveillance System (HDSS), where mortality in the rural area was almost double that of the semi-urban area of Nouna town. ${ }^{5}$ In the Nouna HDSS, different factors such as ethnicity, religion, family-related factors (like number of siblings, birth spacing and age of the mother) or distance to the next health facility, have been shown to influence child survival. ${ }^{6,7}$

Household wealth is one factor which is known to be associated with poor health and mortality in developed countries but only recently came into research focus in developing countries. ${ }^{8-10}$ The strength of the association between household wealth and child mortality depends on the research setting. Several studies showed strong and significant effects of household wealth on child mortality, ${ }^{11-13}$ while other studies did not detect such effects. ${ }^{14-16} \mathrm{~A}$ study from Kenya observed a strong effect of household wealth on child mortality in the rural areas but no effect was shown for children in the urban areas. ${ }^{17}$ 


\section{A. Schoeps et al.}

The aim of this study is to investigate whether there is an association between household wealth and mortality in children under 5 years in Burkina Faso and whether this association differs between the rural and the semi-urban area.

\section{Materials and methods}

\section{Study area and population}

This study was conducted in the Nouna HDSS, which is located in a rural area of north-western Burkina Faso (Figure 1). In 2010, the Nouna HDSS area was inhabited by about 89000 people of different ethnicities and religious beliefs, living in the semi-urban town of Nouna and 58 surrounding villages (Figure 2). ${ }^{18}$ The Nouna HDSS was established by an initial census in 1992. Since then, all households in the study area are visited three times a year to register vital events such as births and deaths, as well as in- and outmigration. The detailed procedures are described elsewhere. ${ }^{19}$

The study area is extremely poor and the number of people with some reading ability is low. Most inhabitants live from subsistence farming. Grid electricity and piped water are available only to dwellers in Nouna town. Health facility density in Nouna HDSS has increased in the recent years. While it was served by one district hospital in Nouna town and only three smaller health centers in 1992, the number of health centers has increased to 13 in the year 2009. ${ }^{18}$

\section{Data collection}

In addition to the continuous vital events registration in the HDSS, a census was conducted in 2009, including a questionnaire on housing characteristics and asset ownership. This questionnaire was filled in for all households in the study area. Information included ownership of assets such as radio, mobile phone, TV or refrigerator, ownership of means of transport, agricultural material and livestock, as well as housing characteristics such as type of walls and roof, source of lighting or the source of water and the type of sanitation (Table 1). By use of the household identification number, census data could be linked with the routine vital events registration database.

\section{Statistical analysis}

An indicator variable for household wealth was created for each of the households in the study area. Principal components analysis (PCA) was used to aggregate information from the census data into one single wealth variable. ${ }^{20}$ Due to the large differences between the rural and semi-urban areas, the PCA was performed separately for Nouna town and the surrounding villages. The poorest households with the lowest values were grouped into quintile 1 , while the wealthiest households were assigned to quintile 5 . For a detailed description of the PCA methods and results, please refer to Supplementary File 1.

This study included all children born between 2005 and 2010 in the Nouna HDSS who could be assigned a respective household wealth quintile. The survival time of children was calculated as the time from birth to death, to the age of 5 years or to the end of follow-up on 31 December 2010, whichever came first. The event of interest was death of a child before the age of 5 years.

Kaplan-Meier curves were used to compare survival between groups defined by wealth quintile and to examine the proportional hazards assumption visually. Two different Cox proportional hazards regression models were calculated for the rural and the semi-urban population. The main explanatory variables were rural and semi-urban wealth quintile. Analysis in the semi-urban population was adjusted for year of birth, ethnicity and religious affiliation. The analysis in the rural population was additionally adjusted for location of living (at main road or more remote) and for living in a village with a health center. Two additional regression models for the rural and the semi-urban areas were calculated with outcome infant mortality. For this purpose, the time variable was set to the time from birth to death, from birth until the age of 1 year or to the end of follow-up.

The proportional hazards assumption for the wealth quintiles in the rural and the semi-urban main models were checked by Schoenfeld residuals visually and by inclusion of interaction terms with the logarithm of time and comparing the likelihood

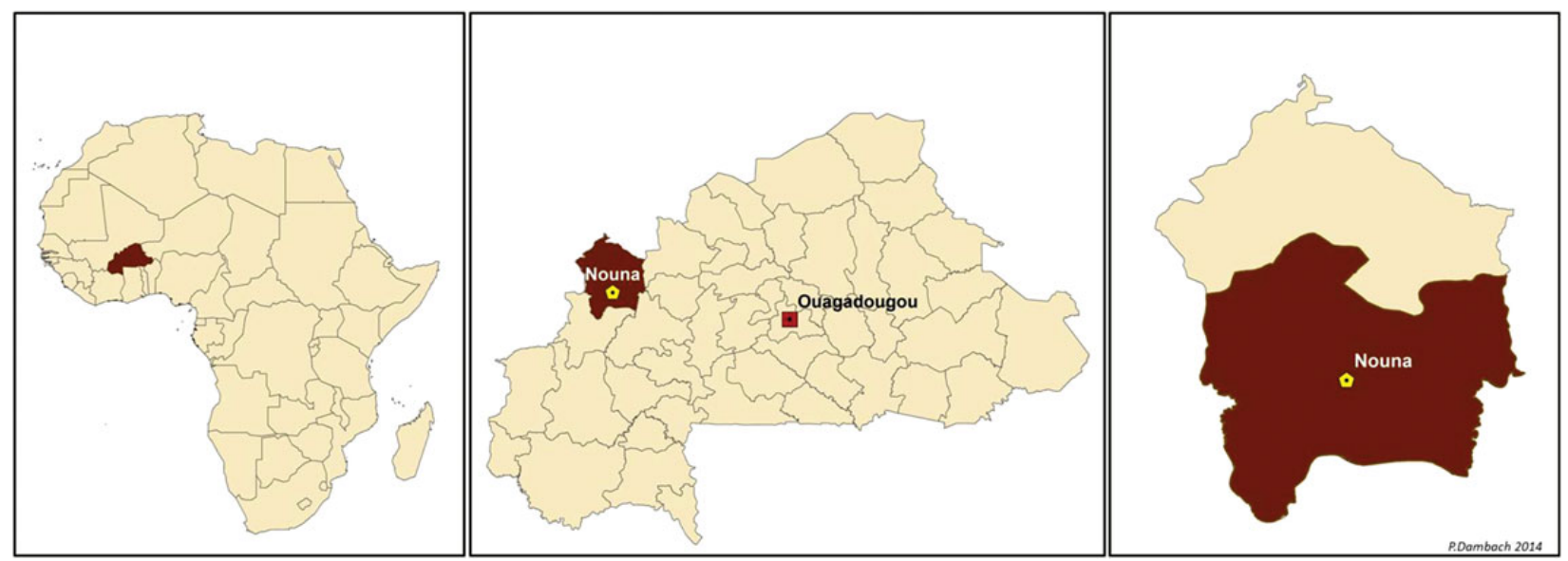

Figure 1. Location of the Nouna Health and Demographic Surveillance System (HDSS) in Burkina Faso. Shaded areas show Burkina Faso (left panel), Kossi province (middle panel) and Nouna HDSS (right panel). Ouagadougou is the capital of Burkina Faso and Nouna town is the capital of the Kossi province. This figure is available in black and white in print and in color at Transactions online. 


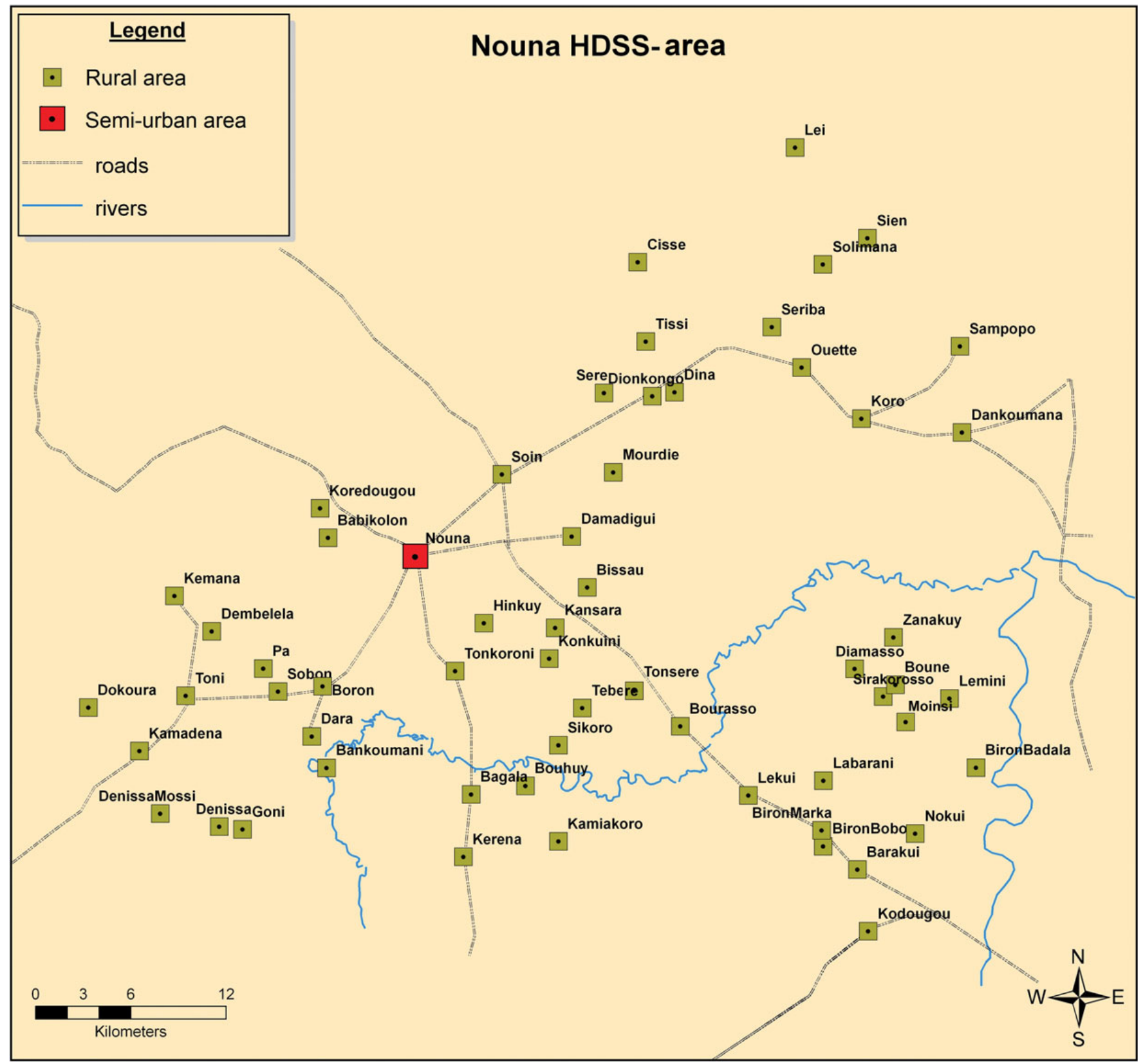

Figure 2. Detailed area map of the Nouna Health and Demographic Surveillance System (HDSS) in Burkina Faso showing rural areas (small squares) and semi-urban areas (large squares). This figure is available in black and white in print and in color at Transactions online.

ratio with and without these interaction terms. All analyses were performed with SAS software, version 9.3 (SAS Institute Inc. Cary, NC, USA).

\section{Results}

Nouna HDSS included about 10000 households in 2009, of which about 10\% (1058/10 213) had to be excluded from PCA due to missing values. For calculation of the wealth indicator, 9155 households (6356 rural and 2799 semi-urban) could be used.
Table 1 shows all variables that were included in the calculation of household wealth in at least one of the areas, with their frequencies and factor loadings from PCA. The eigenvalues of the first principal components constructed for the rural and the semiurban area explained $8.2 \%(5.14 / 63)$ and $10.8 \%(7.44 / 69)$ of the total variance of the 63 and 69 included variables, respectively.

Ownership of most assets was more frequent in the semiurban area than in the rural areas, except agricultural material and livestock such as goats and poultry. Several semi-urban households had access to electricity from the power grid and to piped water, which was inaccessible for the rural households. 
Table 1. Overview of assets used for construction of the rural and semi-urban household wealth indicators. Factor loadings from principal components analysis (PCA) and percent of ownership or mean values among the 9155 households of the Nouna Health and Demographic Surveillance System in 2009

\begin{tabular}{|c|c|c|c|c|}
\hline & \multicolumn{2}{|l|}{ Rural } & \multicolumn{2}{|l|}{ Semi-urban } \\
\hline & Owners (\%) ${ }^{a}$ & Factor loading & Owners (\%) ${ }^{\mathrm{a}}$ & Factor loading \\
\hline \multicolumn{5}{|l|}{ Household assets } \\
\hline Radio & 73.7 & $37^{c}$ & 81.9 & 24 \\
\hline Television & 7.8 & $47^{c}$ & 32.4 & $75^{c}$ \\
\hline Telephone & 27.1 & $52^{c}$ & 63.6 & $47^{c}$ \\
\hline Refrigerator & 0.1 & ND & 8.4 & $58^{c}$ \\
\hline Sewing machine & 2.9 & 16 & 7.8 & 15 \\
\hline Gun & 8.5 & 25 & 5.1 & 18 \\
\hline Modern stove & 0.8 & ND & 9.0 & $68^{c}$ \\
\hline DVD player & 1.6 & 27 & 17.5 & $70^{c}$ \\
\hline Computer & 0.1 & ND & 1.8 & $39^{c}$ \\
\hline Mill & 1.0 & 21 & 0.8 & ND \\
\hline \multicolumn{5}{|l|}{ Means of transport } \\
\hline Motorbike & 24.5 & $67^{c}$ & 36.9 & $60^{c}$ \\
\hline Car & 0.4 & ND & 2.8 & $36^{\mathrm{c}}$ \\
\hline Cart & 41.2 & $52^{c}$ & 40.9 & -17 \\
\hline Bicycles per person & $0.3^{b}$ & 14 & $0.4^{b}$ & 10 \\
\hline \multicolumn{5}{|l|}{ Agricultural material } \\
\hline Plow & 51.7 & $67^{c}$ & 32.8 & -6 \\
\hline Beehive & 2.6 & 0 & 0.1 & ND \\
\hline Pump & 2.0 & 16 & 1.5 & 1 \\
\hline \multicolumn{5}{|l|}{ Livestock } \\
\hline Cattle & 50.2 & $66^{c}$ & 31.9 & -4 \\
\hline Sheep & 37.0 & $64^{c}$ & 35.9 & 1 \\
\hline Goat & 59.1 & $55^{c}$ & 19.5 & -13 \\
\hline Donkey & 44.3 & $52^{c}$ & 39.0 & -17 \\
\hline Pig & 28.3 & 7 & 13.1 & -8 \\
\hline Poultry & 80.4 & $46^{c}$ & 56.7 & -1 \\
\hline Rabbit & 0.7 & ND & 1.4 & 3 \\
\hline \multicolumn{5}{|l|}{ Household size } \\
\hline Persons per room & $2.6^{\mathrm{b}}$ & -11 & $2.0^{\mathrm{b}}$ & -28 \\
\hline \multicolumn{5}{|l|}{ Type of habitation } \\
\hline Hut & 4.6 & 13 & 0.8 & -8 \\
\hline Small house/other & 86.6 & -14 & 82.3 & -18 \\
\hline Building & 8.5 & 6 & 14.8 & 7 \\
\hline Apartment & 0.1 & 2 & 0.1 & 7 \\
\hline Larger house & 0.2 & 7 & 2.0 & $34^{c}$ \\
\hline \multicolumn{5}{|l|}{ Type of walls } \\
\hline Hard & 1.3 & 21 & 8.8 & $62^{c}$ \\
\hline Semi-hard & 1.5 & 21 & 12.4 & $35^{c}$ \\
\hline Banco/other & 96.3 & $-30^{c}$ & 78.7 & -71 \\
\hline Straw & 0.9 & 8 & 0.1 & -1 \\
\hline \multicolumn{5}{|l|}{ Type of roof } \\
\hline Concrete & 0.1 & 1 & 0.2 & 10 \\
\hline Tin & 20.2 & $57^{c}$ & 54.1 & $60^{c}$ \\
\hline Bricks & 0.2 & 1 & 0.4 & -3 \\
\hline Stomped soil & 75.1 & $-60^{c}$ & 44.2 & $-59^{c}$ \\
\hline Straw & 3.7 & 14 & 1.0 & -8 \\
\hline Other & 0.7 & 6 & 0.0 & 8 \\
\hline
\end{tabular}


Table 1. Continued

\begin{tabular}{|c|c|c|c|c|}
\hline & \multicolumn{2}{|l|}{ Rural } & \multicolumn{2}{|l|}{ Semi-urban } \\
\hline & Owners (\%) & Factor loading & Owners (\%) ${ }^{\mathrm{a}}$ & Factor loading \\
\hline \multicolumn{5}{|l|}{ Source of lighting } \\
\hline Power grid & 0.0 & 0 & 37.2 & $74^{c}$ \\
\hline Personal electricity & 0.2 & 3 & 0.2 & 1 \\
\hline Kerosene/gas lamp & 45.1 & -11 & 48.9 & $-55^{c}$ \\
\hline Oil lamp & 3.2 & -10 & 0.4 & -1 \\
\hline Torch/candle & 50.0 & 13 & 12.4 & -25 \\
\hline Wood/straw & 0.3 & -3 & 0.0 & -2 \\
\hline Solar battery & 0.7 & 15 & 0.6 & 4 \\
\hline Other & 0.6 & -4 & 0.3 & -2 \\
\hline \multicolumn{5}{|l|}{ Material for cooking } \\
\hline Energy/gas & 0.6 & 11 & 2.4 & $40^{c}$ \\
\hline Kerosene/coal & 1.5 & 5 & 4.2 & 12 \\
\hline Wood/other & 97.9 & -10 & 93.4 & $-35^{c}$ \\
\hline \multicolumn{5}{|c|}{ Water source in dry season } \\
\hline Piped water & 0 & 0 & 8.5 & $57^{c}$ \\
\hline Drinking fountain & 0.2 & 2 & 34.8 & 18 \\
\hline Pump & 10.6 & 2 & 4.3 & -17 \\
\hline Drilled well & 28.7 & -16 & 6.6 & -12 \\
\hline Usual well/other & 59.6 & 14 & 45.4 & $-36^{c}$ \\
\hline River/dam & 0.8 & -4 & 0.4 & -5 \\
\hline \multicolumn{5}{|c|}{ Water source in rainy season } \\
\hline Piped water & 0 & 0 & 6.5 & $57^{c}$ \\
\hline Drinking fountain & 0.3 & 1 & 14.0 & 22 \\
\hline Pump & 9.4 & 1 & 3.0 & -16 \\
\hline Drilled well & 26.3 & -14 & 7.5 & -9 \\
\hline Usual well/other & 54.7 & 16 & 67.4 & $-34^{c}$ \\
\hline River/dam & 9.4 & -8 & 1.6 & -7 \\
\hline \multicolumn{5}{|l|}{ Type of toilet } \\
\hline Water flushing & 0.1 & 2 & 1.1 & 20 \\
\hline Standard latrine & 13.8 & $35^{c}$ & 33.7 & 21 \\
\hline Ventilated latrine & 6.4 & 18 & 51.2 & -1 \\
\hline Bush/nature/other & 79.8 & $-41^{c}$ & 13.9 & $-34^{c}$ \\
\hline \multicolumn{5}{|l|}{ Type of sanitation } \\
\hline Yard/other & 81.1 & -8 & 53.5 & -15 \\
\hline Street/old well & 17.5 & 8 & 42.3 & 12 \\
\hline Sewer & 0.2 & 1 & 0.8 & 4 \\
\hline Septic tank & 1.3 & 2 & 3.5 & 7 \\
\hline
\end{tabular}

ND: These items were not included for PCA.

a Percentage of households owning the respective item or at least one unit of the respective item.

${ }^{b}$ Mean values instead of owner percentages.

c Factor loadings stronger than 30, positive or negative.

Consequently, most housing characteristics such as source of lighting or source of water more strongly influenced the semiurban wealth variable than the rural household wealth.

During the years 2005 to 2010, 39198 person-years and 1201 deaths in children under 5 years old were observed in our study population, leading to a mortality rate of 30.64 deaths per 1000 person-years (Table 2). Under-5 mortality in the semi-urban area of Nouna town was only about $50 \%$ of that in the rural areas (17 vs 35 per 1000 person-years). For infants, this difference was even stronger with an infant mortality rate of about 21 per 1000 in the semi-urban area and a much higher mortality rate of 52 per 1000 in the rural areas. The probability to survive the first 5 years of life was $93.6 \%$ for semi-urban children and about $88.0 \%$ for rural children. 


\section{A. Schoeps et al.}

Table 2. Person-years, deaths and mortality rate by area wealth quintile in the Nouna Health and Demographic Surveillance System, Burkina Faso, 2005-2010

\begin{tabular}{|c|c|c|c|c|c|c|}
\hline \multirow[b]{2}{*}{ Wealth quintile } & \multicolumn{3}{|c|}{ Under 5 years old } & \multicolumn{3}{|l|}{ Infants } \\
\hline & Person-years & No. of deaths & Mortality $^{a}$ (per 1000) & Person-years & No. of deaths & Mortality $^{\mathrm{a}}$ (per 1000) \\
\hline Semi-urban Q5 & 1375 & 20 & 14.55 & 482 & 9 & 18.67 \\
\hline Semi-urban Q4 & 1990 & 19 & 9.55 & 677 & 7 & 10.34 \\
\hline Semi-urban Q3 & 1908 & 41 & 21.49 & 645 & 16 & 24.81 \\
\hline Semi-urban Q2 & 1771 & 38 & 21.46 & 603 & 18 & 29.85 \\
\hline Semi-urban Q1 & 1644 & 30 & 18.25 & 554 & 12 & 21.66 \\
\hline Semi-urban total & 8687 & 148 & 17.04 & 2961 & 62 & 20.94 \\
\hline Rural Q5 & 8950 & 327 & 36.54 & 3134 & 178 & 56.80 \\
\hline Rural Q4 & 6805 & 221 & 32.48 & 2382 & 115 & 48.28 \\
\hline Rural Q3 & 5664 & 203 & 35.84 & 1950 & 110 & 56.41 \\
\hline Rural Q2 & 4996 & 164 & 32.83 & 1720 & 79 & 45.93 \\
\hline Rural Q1 & 4096 & 138 & 33.69 & 1409 & 69 & 48.97 \\
\hline Rural total & 30511 & 1053 & 34.51 & 10596 & 551 & 52.00 \\
\hline Total & 39198 & 1201 & 30.64 & 13557 & 613 & 45.22 \\
\hline
\end{tabular}

a Mortality for children between birth and the age of 5 years.

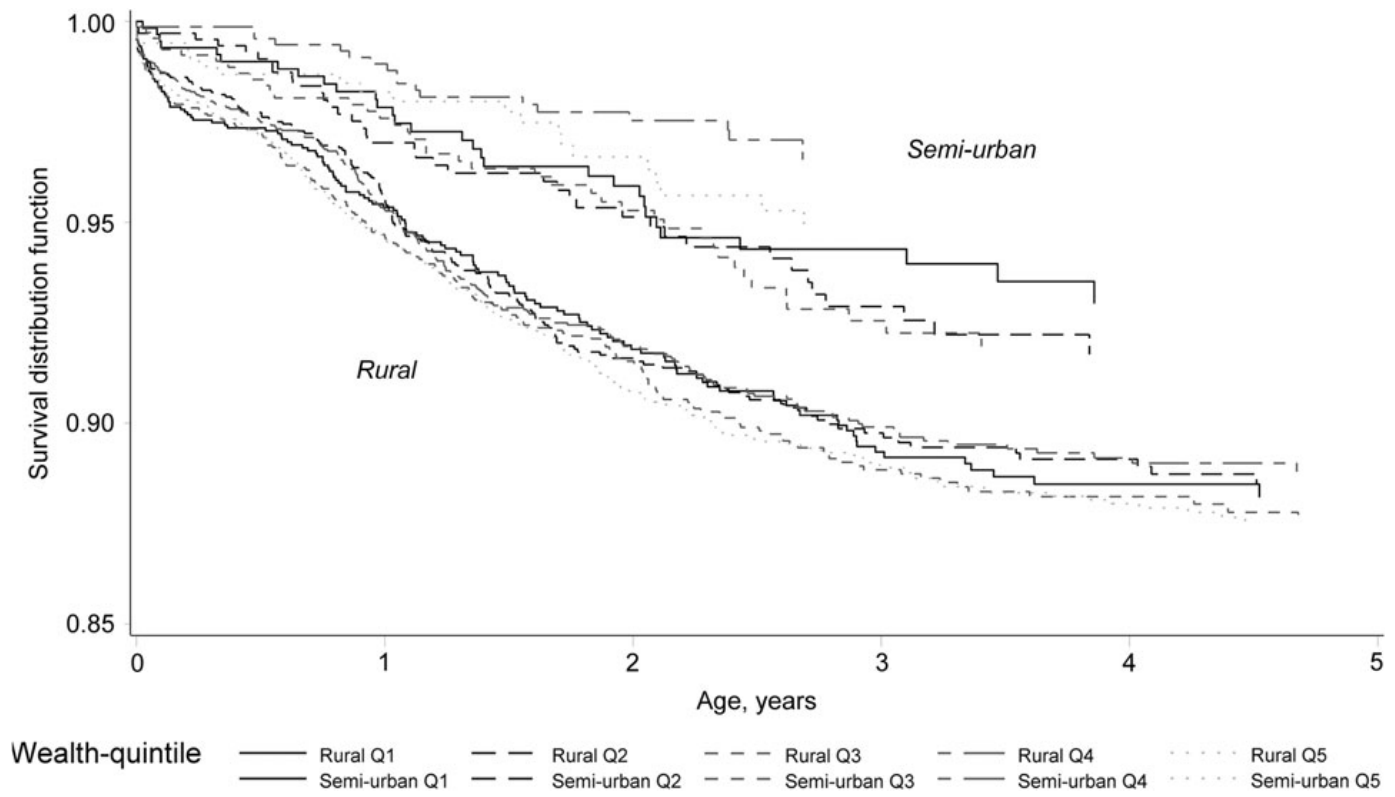

Figure 3. Five-year survival of 15543 children born between 2005 and 2010 in the Nouna Health and Demographic Surveillance System, stratified by area of residence and wealth quintile.

Differences in mortality between wealth quintiles were more strongly pronounced in the semi-urban area than in the rural area: under-5 mortality in Nouna town ranged from 10 to 21 per 1000 person-years. The difference in under-5 mortality in the rural areas was only 5 per 1000 person-years. This is also visible in Figure 3, which shows survival probabilities for children under 5 years old by area of residence and wealth quintile. Curves for the rural area run closely and intersect frequently, while differences between quintiles are clearly visible in the semiurban children. Children in the more deprived quintiles 1-3 show lower survival probabilities as compared to children from the more wealthy quintiles 4 and 5.

In the Cox proportional hazards regression, 12197 and 3346 children were included for analysis in the rural and the semi-urban area, respectively. Results show a significant influence of household wealth on mortality of children under 5 years old living in 
Table 3. The effect of household wealth on mortality of 12197 rural and 3346 semi-urban children under 5 years old in the Nouna Health and Demographic Surveillance System, Burkina Faso, 2005-2010

\begin{tabular}{|c|c|c|c|c|c|c|}
\hline Wealth quintile & Crude HR & Overall $p$-value 2 -sided ${ }^{a}$ & $95 \% \mathrm{CI}$ & Adjusted HR & Overall p-value 2 -sided ${ }^{a}$ & $95 \% \mathrm{CI}$ \\
\hline Semi-Urban Q5 & 1.00 & 0.02 & NA & 1.00 & 0.03 & NA \\
\hline Semi-Urban Q4 & 0.66 & NA & $0.35,1.23$ & 0.64 & NA & $0.34,1.20$ \\
\hline Semi-Urban Q3 & 1.50 & NA & $0.88,2.57$ & 1.43 & NA & $0.83,2.45$ \\
\hline Semi-Urban Q2 & 1.49 & NA & $0.87,2.57$ & 1.40 & NA & $0.81,2.43$ \\
\hline Semi-Urban Q1 & 1.27 & NA & $0.72,2.24$ & 1.26 & NA & $0.70,2.27$ \\
\hline Rural Q5 & 1.00 & NS & NA & 1.00 & NS & NA \\
\hline Rural Q4 & 0.89 & NA & $0.75,1.06$ & 0.90 & NA & $0.76,1.07$ \\
\hline Rural Q3 & 0.99 & NA & $0.83,1.18$ & 0.99 & NA & $0.83,1.19$ \\
\hline Rural Q2 & 0.91 & NA & $0.75,1.09$ & 0.92 & NA & $0.76,1.12$ \\
\hline Rural Q1 & 0.93 & NA & $0.76,1.13$ & 0.94 & NA & $0.76,1.16$ \\
\hline
\end{tabular}

NS: not significant; NA: not applicable.

${ }^{a} p$-values derived from likelihood ratio tests with 4 degrees of freedom between models with and without wealth quintiles.

${ }^{b}$ Semi-urban HR adjusted for year of birth, ethnicity and religious affiliation; rural HR additionally adjusted for peripheral health posts in villages and location at main roads.

the semi-urban area of Nouna town (Table 3). Results show no differences in survival between rural children from different wealth quintiles. For both analyses, adjustment for further variables did not change the estimates reasonably. For both models, inclusion of an interaction term of wealth and time (wealth*time) was not significant in a likelihood ratio test, supporting the proportional hazards assumption.

In the semi-urban area, children from quintiles 2 and 3 seemed to have the highest risk of dying before the age of 5 years, as compared to quintile 5 ( $H R=1.40$ and $H R=1.43$, respectively). Children from quintile 4 seemed to have an advantage in survival compared to children from the wealthiest households $(H R=0.64)$ but this difference was not statistically significant. Nevertheless, when analyzing quintiles in a test for trend, children from more deprived households had a significantly higher risk of dying as compared to children from less deprived households $(p=0.04)$ (results not shown). When restricting analysis to infants (children below 1 year of old), effect estimates were similar to the estimates for under- 5 mortality for both the rural and the semi-urban region. However, as a likely effect of the small number of events (Table 2), results were not significant.

\section{Discussion}

We observed a statistically significant effect of household wealth on under-5 mortality for children residing in the semi-urban area, which was not apparent for rural children. Semi-urban children in the more deprived households were more likely to die than children from richer households. The relation between household wealth and infant mortality was in the same magnitude but not significant at the $5 \%$ level.

The negative effect of wealth on infant and under-5 mortality is in agreement with several previous studies. ${ }^{9-11,13}$ Contrary to the present results, Ettarh and Kimani found that in the rural area in Kenya, household poverty had a significant effect on under-5 mortality, but there was no effect in the urban centers. ${ }^{17}$ Other studies showed significant effects of wealth-related variables, such as piped water and ownership of bicycle, radio or tin roof, on infant and child mortality. ${ }^{12,14}$ Several other studies looked into the association between wealth and child mortality but did not find a significant relationship. ${ }^{15,16,21}$

Household wealth could have affected survival in the present study area in different ways. In very poor households, children are likely to suffer from malnutrition more than children from less deprived households. Malnutrition influences the immune system of the children and is a known risk factor for mortality in children under 5 years. ${ }^{22-24}$ In the Nouna area, health facilities charge for treatment and medication and health insurance coverage of the population is constantly below $10 \%$. Thus, parents from the more deprived households might at times not be able to afford the costs of proper medicine or treatment. ${ }^{25}$

While household wealth was unrelated to under- 5 mortality in the rural areas, mortality rates more than doubled the rates in Nouna town. The magnitude of mortality rates and the rural-urban differences are in line with Burkina Faso's most recent Demographic and Health Survey, although the differences are more pronounced in our study area. ${ }^{4}$ One factor that might explain the different effect of household wealth on mortality between the rural and the semi-urban area is that when looking at the distribution of housing characteristics and asset ownership in the present study area, more pronounced differences were seen in the semi-urban population, while the rural population appeared more homogeneous (Supplementary Table 1). Community goods such as electricity and piped water were not available in the rural area and differed markedly between semi-urban quintiles. In a sensitivity analysis in the semi-urban population, including electricity and piped water as substitutes for the more complex construct household wealth, strong but non-significant effects were found. This indicates that differences in under-5 mortality are 
not only ascribed to differences in community goods but also depend on individual differences.

The rural population was very homogeneous, especially with regards to housing materials and most household assets. This might have prevented adequate distribution of households into wealth quintiles. Vyas and Kumanarayake ${ }^{27}$ found that in rural Ethiopia it was not possible to construct a socio-economic status score by PCA because of the uniform poverty in the area that can lead to truncation of the socio-economic status score at the lower end. ${ }^{26}$ However, when looking at the distribution of assets and housing materials between the wealth quintiles (Supplementary Table 1), it seems unlikely that households were indeed uniform with regard to all variables considered for the construction of the wealth quintiles. Another factor, which might explain the uniform mortality risk between wealth quintiles from the rural area, is that ownership of assets and housing characteristics are commonly regarded as indicators of long-run wealth as opposed to current availability of money, which can be spent on food or health services. ${ }^{20,27}$ Houweling et al. suggest the inclusion of food sufficiency into a wealth indicator to better express real deficiency of money. ${ }^{28}$

It is a strength of this study that longitudinal data on survival for more than 15000 children born in the Nouna HDSS could be used, where information on births and deaths are collected regularly in the complete study region. From the additional census a large number of variables to describe the household wealth were available, including information on agricultural material and livestock. Due to the availability of further information such as ethnicity, religious affiliation and the location of health centers in the study area, we were able to separate the effect of these factors from the effect of household wealth.

One limitation of this study is that education of the parents was not assessed in the census questionnaire or the routine HDSS procedures, so analyses could not be adjusted for this factor. From a vaccination survey in children under 5 years old in 2008/9 it is estimated that $88 \%$ of all mothers in the study area are illiterate. $^{27,29}$

Data assessed for the households in 2009 were extrapolated to all children born between 2005 and 2010, which could have led to misclassification. However, household assets are assumed to be a slowly changing indicator of long-run wealth and have commonly been extrapolated to preceding and subsequent years. ${ }^{14,16,17}$ Several assets might be changing at a faster rate than others, which might be especially true for livestock and this was important for the construction for the rural wealth score. However, a sensitivity analysis for the rural area restricted to children born between 2008 and 2010 yielded comparable results.

A number of sensitivity analyses were performed regarding the suitability of PCA to derive a wealth score in this context. The description and discussion of the results are presented in Supplementary File 2.

\section{Conclusions}

In conclusion, this study supports findings from many other developing countries where childhood mortality was shown to be lower in urban compared to rural areas. Mortality in the Nouna area in Burkina Faso was associated with household wealth in the semiurban but not in the rural areas, which might be explained by better access to electricity, clean water and better health services. As these community-related factors seem to determine child survival more than individual factors such as household wealth, authorities should aim to increase coverage of these services to rural areas.

\section{Supplementary data}

Supplementary data are available at Transactions Online (http://trstmh.oxfordjournals.org/).

Authors' contributions: ASo, HB and ASc conceived the study; LN, ED and ASi conceived the data collection; GK was responsible for data management and validation; ASC and HB conducted the data analysis; ASc drafted the manuscript. OM, HB and ASo critically revised the manuscript for intellectual content. All authors read and approved the final manuscript. ASc is the guarantor of the paper.

Acknowledgements: The authors would like to thank the staff of the Centre de Recherche en Santé de Nouna, who are responsible for all data collection and entry processes in the Health and Demographic Surveillance System.

Funding: This study was supported by the European Union under the title 'Optimising the impact and cost-effectiveness of child health intervention programs of vaccines and micronutrients in low-income countries (OPTIMUNISE)', [FP7-HEALTH-F3-2011-261375].

Competing interests: None declared.

Ethical approval: Not required.

\section{References}

1 United Nations. The Millennium Development Goals Report 2013. New York; United Nations; 2013. http://www.un.org/millennium goals/pdf/report-2013/mdg-report-2013-english.pdf [accessed 25 July 2013].

2 Bryce J, Victora CG, Black RE. The unfinished agenda in child survival. Lancet 2013;382:1049-59.

3 The Republic of Burkina Faso, Ministry of Economics and Planning and United Nations. Rapport pays de suivi de la mise en oeuvre des objectifs du millenaire pour le developpement Burkina Faso, OMD en 2010. Ouagadougou, Burkina Faso; 2010 [in French]. http://planipolis. iiep.unesco.org/upload/Burkina\%20Faso/Burkina\%20Faso_MDG Report_2010_FR.pdf [accessed 17 June 2014].

4 Institut National de la Statistique et de la Démographie (INSD) and ICF International. Enquête Démographique et de Santé et à Indicateurs Multiples du Burkina Faso 2010. Calverton Maryland: ICF International; 2012. http://www.measuredhs.com/pubs/pdf/FR256/ FR256.pdf [accessed 4 June 2013].

5 Sié A, Niamba L, Diboulo E et al. Rapport Annuel 2011: Système de surveillance démographique et de santé (SSDS) de Nouna. Ministère de la Santé, Secrétariat Général, et Centre de Recherche en Santé de Nouna, Burkina Faso; 2011 [in French]. http://

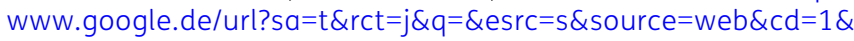
ved=0CCIQFjAA\&url=http $\% 3$ A $\% 2 F \% 2 F w w w . c r s n-n o u n a . b f \% 2 F r e$ sources\%2Fcariboost_files\%2FRapport_HDSS_202011_FINAL_2012 20octobre_202012.docx\&ei=9kqgU5KzIKuA7̄QaymIHABQ\&usg=AF 
QjCNHsNkbE_zLqW5D4OABHOGJfAyD2bQ\&bvm=bv.68911936,d.ZGU [accessed 17 June 2014].

6 Becher H, Müller O, Jahn A et al. Risk factors of infant and child mortality in rural Burkina Faso. Bull World Health Organ 2004; 82:265-73.

7 Schoeps A, Gabrysch S, Niamba L et al. The effect of distance to health-care facilities on childhood mortality in rural Burkina Faso. Am J Epidemiol 2011;173:492-8.

8 Braveman P, Gruskin S. Poverty, equity, human rights and health. Bull World Health Organ 2003;81:539-45.

9 Houweling TA, Kunst AE. Socio-economic inequalities in childhood mortality in low- and middle-income countries: a review of the international evidence. Br Med Bull 2010;93:7-26.

10 Wagstaff A. Socioeconomic inequalities in child mortality: comparisons across nine developing countries. Bull World Health Organ 2000;78:19-29.

11 Adebowale AS, Yusuf BO, Fagbamigbe AF. Survival probability and predictors for woman experience childhood death in Nigeria: "analysis of North-South differentials". BMC Public Health 2012;12:430.

12 Armstrong Schellenberg JR, Nathan R, Abdulla $S$ et al. Risk factors for child mortality in rural Tanzania. Trop Med Int Health 2002;7:506-11.

13 Nattey C, Masanja H, Klipstein-Grobusch K. Relationship between household socio-economic status and under-five mortality in Rufiji DSS, Tanzania. Glob Health Action 2013;6:19278.

14 Manda SO. Birth intervals, breastfeeding and determinants of childhood mortality in Malawi. Soc Sci Med 1999;48:301-12.

15 Deribew A, Tessema F, Girma B. Determinants of under-five mortality in Gilgel Gibe Field Research Center, Southwest Ethiopia. Ethiop J Health Dev 2007;21(2).

16 Kembo J, Van Ginneken JK. Determinants of infant and child mortality in Zimbabwe: Results of multivariate hazard analysis. Demographic Res 2009;21:367-84.

17 Ettarh RR, Kimani J. Determinants of under-five mortality in rural and urban Kenya. Rural Remote Health 2012;12:1812.
18 Sié A, Louis VR, Gbangou A et al. The Health and Demographic Surveillance System (HDSS) in Nouna, Burkina Faso, 1993-2007. Glob Health Action 2010;14:3.

19 Becher H, Kouyaté B. Health Research in Developing Countries: A collaboration between Burkina Faso and Germany. Heidelberg, Germany: Springer; 2005.

20 Filmer D, Pritchett LH. Estimating wealth effects without expenditure data-or tears: an application to educational enrollments in states of India. Demography 2001;38:115-32.

21 Diallo AH, Meda N, Ouedraogo WT et al. A prospective study on neonatal mortality and its predictors in a rural area in Burkina Faso: can MDG-4 be met by 2015? J Perinatol 2011;31:656-63.

22 Black RE, Allen LH, Bhutta ZA et al. Maternal and child undernutrition: global and regional exposures and health consequences. Lancet 2008;371:243-60.

23 Chimhuya S, Kambarami RA, Mujuru H. The levels of malnutrition and risk factors for mortality at Harare Central Hospital-Zimbabwe: an observation study. Cent Afr J Med 2007;53:30-4.

24 Müller $\mathrm{O}$, Krawinkel M. Malnutrition and health in developing countries. CMAJ 2005;173:279-86.

25 Gnawali DP, Pokhrel S, Sie A et al. The effect of community-based health insurance on the utilization of modern health care services: evidence from Burkina Faso. Health Policy 2009;90:214-22.

26 McKenzie DJ. Measuring Inequality with Asset Indicators. J Popul Econ 2005;18:229-60.

27 Vyas S, Kumaranayake L. Constructing socio-economic status indices: how to use principal components analysis. Health Policy Plan 2006;21:459-68.

28 Houweling TA, Kunst AE, Mackenbach JP. Measuring health inequality among children in developing countries: does the choice of the indicator of economic status matter? Int J Equity Health 2003;2:8.

29 Schoeps $A$, Ouedraogo N, Kagone $M$ et al. Socio-demographic determinants of timely adherence to BCG, Penta3, measles, and complete vaccination schedule in Burkina Faso. Vaccine 2013;32:96-102. 